\title{
Monitoring new psychoactive substances: Exploring the contribution of an online discussion forum
}

\author{
Rhumorbarbe D.a,b, Morelato M. ${ }^{\mathrm{b}}$, Staehli L.a, Roux C. ${ }^{\mathrm{b}}$

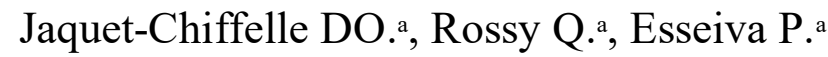 \\ aEcole des Sciences Criminelles, University of Lausanne, Lausanne, Switzerland. \\ bCenter for forensic sciences, University of Technology, Sydney, Australia.
}

\begin{abstract}
Background: The rapid emergence of new psychoactive substances (NPS) is a challenge for public health authorities and law enforcement. The phenomenon is strengthened since the increase of the Internet usage. Not only used to trade NPS, the Web is an important source of information for both potential drug consumers and experienced users. Discussion forums are among these sources of information. They are meeting points for different groups of users and include a wide range of trip reports, questions and consumption tips. Since the discussions are archived over a long period, they can be used to monitor the interest of consumers for particular substances over time. This research aims at understanding the contribution of data extracted from a major online discussion forum within a systematic monitoring process.

Method: Data were collected from a discussion forum (i.e. Drugs-forum). Within the sections of the forum, the titles, content of discussion, number of replies, and the date of the first discussion were crawled and stored in a dedicated database. The intensity of the discussions related to 42 substances considered as NPS was measured through an indicator allowing to assess the popularity of substances. Furthermore, the appearance of 15 substances on the forum was compared to the date of formal notification to the EU early warning system.

Results: An evolution of the different classes of substances, as well as an evolution of specific substances within a class were highlighted. Some substances were discussed for a long period of time (e.g. Kratom, 25i-NBOMe, MDPV) while others were discussed very briefly (e.g. 5-MeO-DPT, NM-2AI). Out of the fifteen substances subjected to a risk assessment from the European Monitoring Centre for Drugs and Drug Addiction (EMCDDA), nine of them appeared on the forum before or at the same time as their first date of notification to the EU early warning system.

Conclusion: In line with previous research on doping products, this article shows the potential of the monitoring of online forums in the context of psychoactive substances. Besides, the system designed to collect the data is flexible and can be systematically updated to fuel a monitoring process. It informs not only on the presence/absence of a substance in discussions between consumers, but also on its evolution over time. Such results could benefit academic research and organizations studying the NPS phenomenon. Precisely, it could complement existing early warning systems and benefit law enforcement agencies and policy makers.
\end{abstract}

Keywords: forensic intelligence ; early-warning ; harm reduction ; popularity

\section{Introduction}

New psychoactive substances (NPS) constitute a challenge for both public health and law enforcement authorities. There is a large number of substances that are monitored by international organisations such as the European Monitoring Centre for Drugs and Drug Addiction (EMCDDA) (EMCDDA \& Eurojust, 2016) or the United Nations on Drugs and Crime (UNODC) (UNODC, 2017). However, the rate at which they are emerging causes difficulties for existing reactive systems of drug control. A modification of the substance structure can easily be done once the legislation to prohibit this substance is passed (Chatwin, Measham, O'Brien, \& Sumnall, 2017). In terms of control and policy, there is no uniform legal framework between countries to address the problem of new psychoactive substances (King, 2013). Furthermore, the definition of NPS itself raises concerns within the scientific community. For instance, these substances are sometimes referred to as "legal highs" or "research chemicals", even though such terms are not appropriate (Corazza, Demetrovics, van den Brink, \& Schifano, 2013). What makes the substances "new" or "novel" is also debated, with authors arguing that the novelty is due to the fact that the substances are newly-abused (King, 2013), while others refer to the lack of knowledge about them (Potter \& Chatwin, 2018). In the last few years, technologies have offered new opportunities to extend and diversify the trade of illicit and licit drugs and exchange information. The Web is the main application used on a daily basis by millions of users, and thus the central location on which illicit trade has developed. The other applications - such as those designed for messaging or peer-to-peer 
purposes - are also used as a vector to promote illicit trafficking, even though they have not been extensively studied in that context so far (Kruithof et al., 2016; Rossy \& Décary-Hétu, 2018). Most academic research regarding online illicit trade on the Web has focused on the trafficking of both illicit drugs and NPS (Barratt \& Aldridge, 2016; EMCDDA, 2016, 2017a; Kruithof et al., 2016). The former seems to be mainly accessible on cryptomarkets on Dark Webs 1 (using protocols such as TOR or I2P), while the latter appears to be more visible on the Web, since they are not necessarily illegal - or at least not yet in many countries - according to the major conventions on narcotic drugs (i.e. Single Convention on Narcotic Drugs of 1961, and Convention on Psychotropic Substances of 1971).

The Psychonaut 2002 project and its subsequent developments such as the ReDNet project (Corazza, Assi, et al., 2013; Psychonaut Web Mapping Research Group, 2005) aimed to gather information from online sources to improve the knowledge of the phenomenon. In the first project, they highlighted a range of online resources related to NPS (i.e. forums, blogs, information website and online shops). Then, discussion forums were studied in more details, by reading their content and monitoring new posts regularly. This task was described as time-consuming, though very informative since the content of the forum was deemed exclusive and relevant. At the time of the study, no other sources of information provided such an exhaustive picture of the consumers' point of view. Building on these findings, the Psychonaut Web Mapping project produced technical reports about 31 substances, fuelled by literature review and information gathered online (in particular, chemical and physical characteristics, price, route of administration, legal status, misuse, combinations and effects) (Psychonaut Web Mapping Research Group, 2010).

Other studies have focused on the analysis of web shops offering NPS. According to the EMCDDA-Europol (2016) 651 web shops were identified on the Web in 2013 (EMCDDA \& Europol, 2016). More recently, the iTrend project offered a multidisciplinary approach to conduct test purchases of different substances through the Web. Some NPS offered for sales turned out to be different from what was advertised, with also important variations in purity (Brunt et al., 2017; EMCDDA, 2016). The websites on which these substances were sold were studied, revealing specific strategies (e.g. free samples, testimonials or efforts to suggest the website authenticity) used by the vendors to market their substances (Meyers et al., 2015). Monitoring such websites over time indicated that the market has changed, with new substances emerging regularly. For example, a monitoring process applied to a selection of 43 web shops over twelve months highlighted ten new products per month (Bruno, Poesiat, \& Matthews, 2013).

Apart from hosting web shops, the Web is also a source of information for both potential drug consumers and experienced users. In the context of NPS, discussion forums are a meeting point for these groups of users and include a wide range of questions, answers and consumption tips. The potential of discussion forums to provide insights into the appearance of novel substances on the market was highlighted in the literature (Sedefov, Gallegos, Mounteney, \& Kenny, 2013). Several qualitative and quantitative studies focused on the content of discussion forums. For example, the history of the first generation of synthetic cannabinoids was divided into three phases (i.e. 'enthusiasm', 'scepticism' and 'rejection') through the analysis of a Norwegian forum (Bilgrei, 2016). From a Swedish perspective, trip reports posted on the Flashback forum about synthetic cannabinoids revealed the intoxicating power of these products, as well as both positive and negative effects (Kjellgren, Henningsson, \& Soussan, 2013). The addition of eight compounds to the Swedish list of controlled substances impacted on the daily number of messages posted on this forum (Ledberg, 2015). Finally, discussion forums may also be used to spread surveys or recruit participants for interviews in order to study NPS use and consumers (Soussan \& Kjellgren, 2016). Discussion forums are also found on the Dark Web and may be linked to specific cryptomarkets. The forums of four cryptomarkets - AlphaBay, Valhalla, Dream market and Nucleus - were qualitatively studied, highlighting specific themes of discussion related to particular aspects of NPS (e.g. motives of use, trafficking and reputations of sellers) (Van Hout \& Hearne, 2017).

Anticipation is a primary objective in the context of the NPS phenomenon, as shown by the efforts of the UNODC and EMCDDA to develop early-warning systems. In parallel, literature reveals that the Web plays a major role in the NPS market, since some websites or discussion forums are used to promote, sell and discuss NPS. Even if the market is not entirely concentrated online, the Web may constitute another rich source of information that could be used in an early-warning perspective. In the context of academic research, drug discussion forums have been qualitatively studied or used as part of multiple datasets (Psychonaut Web Mapping Research Group, 2005, 2010). While this type of research is essential to understand how such datasets might be used, they are difficult to reproduce and time-consuming since they imply a lot of

1 In the context of this research, we distinguished between the Web - maintained and regulated by the major Internet organisations - and the Dark Web - self-regulated parts of the Web accessible via specific protocols (e.g. TOR or I2P). A further distinction between the 'Clear Web' and the 'Deep Web' is possible, depending on whether or not search engines are able to reference the content of the webpages. The 'Deep Web' is not considered for this research. 
readings and manual classification.

This research aims at understanding the contribution of data extracted from an online discussion forum within a systematic monitoring process. A systematic approach - combined with the right degree of automatisation - could produce a monitoring process based on multiple iterations of the data gathering and analysis steps. The word systematic implies that the data collection process gather the content of an entire forum (or a forum section) and structure the data so that all the relevant content of the forum can be analysed subsequently. The analysis process and the detection of patterns would thus rely on the complete content and provide a more accurate understanding of substances of interest.

To address this aim, data extracted from the Drugs-forum website were used to study the interest of consumers over time about selected substances and compare the results to the literature about these substances. Drugs-forum is hosted on the Web and is a major discussion forum covering drugs in general, with an important focus on harm reduction. As such, it informs on the practice of consumers and appears to be more appropriate than cryptomarkets forums which would include discussion about transactions, dispute between sellers and vendors and other topic specific to cryptomarkets, rather than NPS-related exchange of information. This research is a proof of concept and has the potential to bring complementary and new information about these new psychoactive substances in terms of use and interest by consumers. Pineau et al. (2016) described such a process in their research about doping products. In the context of NPS, monitoring substances through the analysis of discussion forums could help identify the most discussed substances among consumers. Such a result could be used as a proxy to assess the popularity of substances over time. A process similar to the one described in the present research could not only be used in an academic context, but also by organizations involved in the early detection and monitoring of the NPS phenomenon. It could help target efforts (i.e. law enforcement as well as prevention) on specific problematic substances and help policy makers and practitioners to make progress in responding to this "new" phenomenon. As such, it would help strength the already in place early-warning systems.

\section{Dataset and methodology}

\subsection{Data collection}

Drugs-forum opened in 2003 and now includes more than 250,000 registered members and a wide range of discussions (i.e. more than 220,000 discussion threads). This forum was chosen because of its size. Indeed, it may be considered as a public space since hundreds of thousands of people are present on it. Moreover, the terms of use of the forum (https://drugsforum.com/wiki/Terms_of_Use) defined the content of the sections as publicly posted. No personal data such as pseudonym or specific verbatim were used in the research. In line with previous research on drug forum (Van Hout \& Hearn, 2017) and for ethical and privacy reasons (i.e. to avoid putting individuals at risk of prosecution and/or disrupting a safe space for stigmatised individuals), all results presented are aggregated and cannot be linked to any virtual identity.

The subsections of this forum listed in the section "Drug information \& harm reduction" were considered for this study. A Python-coded system was designed to crawl the Drugs-Forum website and scrape the data (versions: Python 2.7 and its library BeautifulSoup 4.4.0). Briefly, this system takes as an input the sections' main URL (i.e. web address) and builds a list of its respective following pages. All these pages are then browsed, data related to each discussion thread is duplicated (restructured if necessary) and stored into a dedicated database. Data related to 84,678 discussion threads was collected. In particular, the title of each thread was extracted, as well as its date of creation, and the number of views and replies it generated. The number of users who took part in the discussions was also recorded. Further analysis was conducted using the Tableau Desktop 10.5 visualisation software.

\subsection{Targeted substances}

The United Nations Office on Drugs and Crime (UNODC) categorises NPS in nine classes namely phenethylamines, synthetic cannabinoids, synthetic cathinones, piperazines, tryptamines, aminoindanes, phencyclidine-type substances, plant-based substances, and other substances (https://www.unodc.org/LSS/SubstanceGroup/GroupsDashboard?testType=NPS). A selection of the most common NPS reported to the UNODC Early Warning Advisory on NPS was made to cover each class (except the category "other substances" due to its unclear nature). Table 1 summarizes the 42 substances selected. The complete name of each substance is detailed in Table 3, in the Appendix.

It is important to mention that some substances in Table 1 might not be considered as NPS anymore in certain countries due to legislative changes (e.g. khat, MXE). Although it may be seen as a limitation, a deeper knowledge about these substances is likely to be available in the literature since they have been known for at least a few years. In the context of a proof of concept, previous research about these substances would provide information that could be compared to our findings. They were thus considered in this study as they might help assess the contribution of discussion forums analysis for early-warning 
purposes.

Table 1. Targeted substances

\begin{tabular}{|c|c|c|c|}
\hline Class & Substance & Class & Substance \\
\hline \multirow[t]{9}{*}{ 1/ Phenethylamines } & PMMA & 4/ Piperazines & $\mathrm{BZP}$ \\
\hline & 25c-NBOMe & & MBZP \\
\hline & 25i-NBOMe & & $\mathrm{mCPP}$ \\
\hline & $2 \mathrm{C}-\mathrm{E}$ & & MT-45 \\
\hline & 2C-T-2 & & PFPP \\
\hline & 4-FA & & TFMPP \\
\hline & $5-\mathrm{APB}$ & 5/ Tryptamines & AMT \\
\hline & 6-APB & & 4-AcO-DipT \\
\hline & 2-CB-FLY & & 4-AcO-DMT \\
\hline \multirow{7}{*}{$\begin{array}{l}\text { / Synthetic } \\
\text { cannabinoids }\end{array}$} & HU-210 & & 5-MeO-DMT \\
\hline & JWH-018 & & 5-MeO-DPT \\
\hline & JWH-073 & 6/ Aminoindanes & MDAI \\
\hline & JWH-250 & & NM-2AI \\
\hline & AM-2233 & +2 & $2-\mathrm{AI}$ \\
\hline & APINACA & 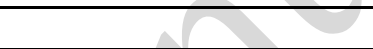 & 5-IAI \\
\hline & AB-PINACA & 7/ PCP-type substances & MXE \\
\hline \multirow[t]{5}{*}{ 3/ Synthetic cathinones } & a-PVP & 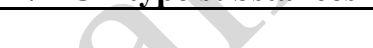 & 4-MEO-PCP \\
\hline & MDPV & 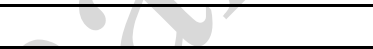 & 3-MEO-PCP \\
\hline & Mephedrone & $\begin{array}{l}\text { 8/ Plant-based } \\
\text { substances }\end{array}$ & Khat \\
\hline & n-ethyl-pentylone & $y^{\prime}$ & Kratom \\
\hline & 3-FMC & 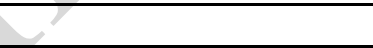 & Salvia divinorum \\
\hline
\end{tabular}

A specific analysis was carried out on 15 substances (see Table 2) that were the subject of risk assessments by the EMCDDA between 1999 and 2017 (EMCDDA, 2010; Sedefov et al., 2013).

Table 2. Targeted substances that were the subject of an EMCDDA Risk

\begin{tabular}{|l|l|l|}
\hline Class & Substance & Date of report \\
\hline 1/ Phenethylamines & 25i-NBOMe & 2014 \\
\hline & $4,4^{\prime}-$ DMAR & 2014 \\
\hline & 5-IT & 2013 \\
\hline 2/ Synthetic cannabinoids & ADB-CHMINACA & 2017 \\
\hline & CUMYL-4CN-BINACA & 2017 \\
\hline & AB-CHMINACA & 2017 \\
\hline & 5F-MDMB-PINACA & 2017 \\
\hline & MDMB-CHMICA & 2016 \\
\hline 3/ Synthetic cathinones & a-PVP & 2015 \\
\hline & MDPV & 2014 \\
\hline & Mephedrone & 2010 \\
\hline 4/ Piperazines & BZP & 2007 \\
\hline & mCPP & 2005 \\
\hline & MT-45 & 2014 \\
\hline 7/ PCP-type substances & MXE & 2014 \\
\hline
\end{tabular}




\subsection{Choice of indicator}

The indicators available to assess the popularity of a substance were the number of views, the number of replies, the number of distinct authors involved in a discussion thread, and the number of threads related to this substance (Pineau et al., 2016). Regular expressions were used to search for the name of substances in the titles while taking into account the variations of a substance name (e.g. JWH-018 might also be written 'JWH 018', 'Jwh018', etc). A matrix of Spearman's rank correlation coefficients was calculated between each of the indicators, for every substance in Table 1. Each calculated correlation was above 0.93 ( $\mathrm{p}$-value $<0.001$ ). Thus, any indicator may be chosen to assess the popularity of a substance. Knowledge about the way the forum works may complement such correlation and help selecting an indicator. For instance, Pineau et al. (2016), in their research on forums about doping products, based their choice of indicator on the fact that some authors may "flood" discussion threads. Flooding is indeed a common practice on forums about doping products, where vendors may advertise for their brands or their web shop. In contrast, for the present research, this problem won't occur and the cumulative number of replies across all threads related to a substance was selected to assess its popularity. It is worth noting that the indicator used in the present research is a reflection of the intensity of the discussions related to a substance. This measure of intensity is used as a proxy to estimate the popularity of a substance among the users of an online forum. This estimation of popularity has limitations and will be discussed in more detail in section 4. In particular, the negative side effects of a substance may fuel discussion (e.g. 'reverse popularity'). Alternatively, the substance may still be popular but the intensity of discussions may decrease or cease entirely because existing threads may have covered every topic and question related to that substance. In such cases, the substance could still be popular but its popularity not being reflected in discussion intensity.

The other indicators were not chosen since they might not reflect users' interest in a substance. For example, the number of views is not necessarily related to the activity of the population of interest (i.e. consumer). Its incrementation depends on how the website is working (i.e. different ways of counting multiple connections with a same IP address). The number of threads might be misleading as a small part of them concentrate the majority of the discussions. Some of these "mega-threads" are sometimes used to gather as much information as possible, while some precise questions or trip reports are the subject of specific threads. The same applies to the number of distinct first authors, since some forum users - moderators for instance may start discussions more often than other users. Thus, the number of replies was chosen as an indicator for each substance.

\subsection{Analysis}

First, the timeframe during which a substance was present (i.e. discussed) on the discussion forum was calculated and represented over time. Secondly, the changes in popularity of this substance over time were studied in more details. Two conditions were required to consider a substance as being present on Drugs-forum during a given month. First, threads related to the substance should have replies over the month. Second, the monthly number of replies related to this substance represented at least $1 \%$ of the total number of replies across the threads related to this substance. The timeframe during which a substance was present on the forum was then visualised. This timeframe starts with the creation date of the first thread discussing the substance. It ends with the creation date of the last thread that generated at least $1 \%$ of the replies, without considering any interruption.

Changes in popularity for each substance was investigated over the timeframe. As performed by Pineau et al. (2016) in the context of doping products, the number of replies was normalised and represented over time. Different patterns were then highlighted visually (i.e. chronic, downward, upward), as well as particular peaks of interest.

When a substance was the subject of an EMCDDA risk assessment, the first official notification of the substance through the early warning system was systematically mentioned in the risk assessment report. For the 15 selected substances, this date was compared to the appearance of the substances on the forum.

\section{Results and discussion}

\subsection{Presence of the forty-two NPS on the forum}

Figure 1 summarises the length of discussion of the forty-two substances selected on the Drugs-forum over the 2003-2018 period. 
Figure 1. Presence of each substance on the forum (at least $1 \%$ of the total number of replies across the threads related to a substance).

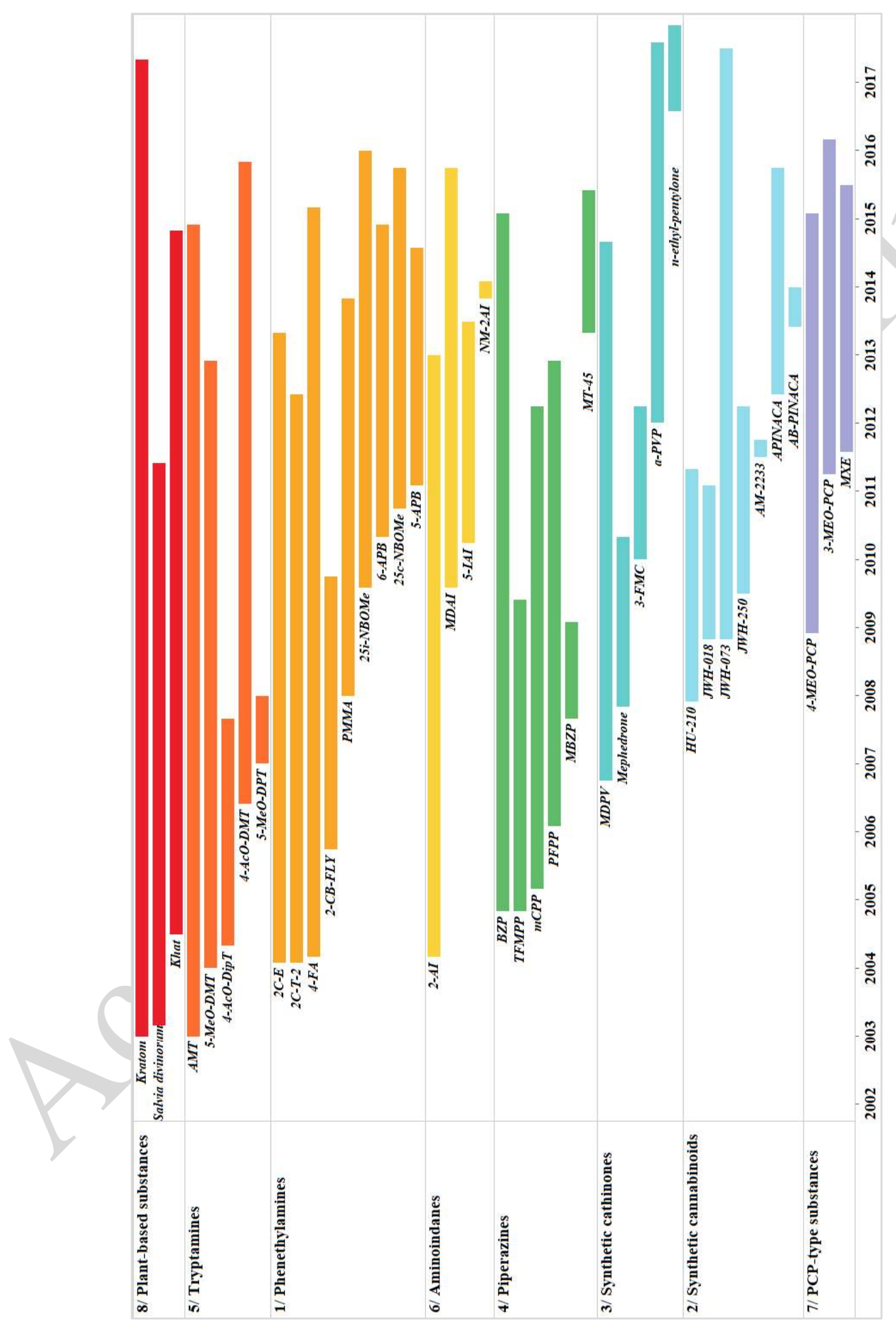


It is interesting to note an evolution of the different classes of substance as well as the evolution of particular substances within a same class. Some substances have been discussed over a long period of time (e.g. kratom, salvia divinorum, AMT) while others were discussed very briefly (e.g. 5-MeO-DPT, NM-2AI, AM-2233). For example, plant-based substances have been traditionally consumed for a long time in specific regions (e.g. khat was originally consumed in Eastern Africa, kratom in South East Asia and Salvia divinorum in Central America) before being classified as NPS (Feng, Battulga, Han, Chung, \& Li, 2017; Gibbons \& Arunotayanun, 2013), while synthetic compounds were manufactured more recently (e.g. NM-2AI). In contrast, a succession in the appearance of synthetic cannabinoids and synthetic cathinones is observed. A similar trend was reported in the literature where different generations of these classes subsequently appeared on the market (Watterson \& Foster Olive, 2014; Wilson-Hohler, Fathy, \& Mozayani, 2016). The trends drawn by analysing this online discussion forum reflect the information from the literature. This tends to confirm that such forums are a valid source to monitor the appearance of substances on the market.

Some substances (e.g. khat, BZP, 2-AI, 5-IAI, 4-AcO-DipT) were discussed on the forum but only sporadically reported in the literature or reported in a particular population. For example, the prevalence of aminoindanes was considered as very low in 2013 (Brandt, Braithwaite, Evans-Brown, \& Kicman, 2013). This could explain why two of them - 2-AI and 5-IAI - were not discussed after 2013. Similarly, 4-AcO-DipT seems to be particularly anecdotal in terms of seizures and use (Greene, 2013). Khat is used by very specific migrant populations. Some of them migrated to Europe and America, explaining why this kind of substance has spread across the world (Gibbons \& Arunotayanun, 2013). Most of the forum discussions related to this substance are about cultivation, which is in line with the fact khat does not seem to be offered for sale on the Web (EMCDDA, 2015). The legislation regarding plant-based substances is likely to influence the discussion on the forums. It took a long time for plant-based substances to be controlled and thus the length of their discussion on the forum might be related to that. For example, the commerce of khat is controlled by the UK Psychoactive Substances Act of 2016, while the question is still debated in the United States. Similarly, kratom - a plant originally grown in Asia - has been discussed for a long time on the forum, probably because it was not controlled in Europe until 2011 and only in a few countries (EMCDDA, 2015).

\subsection{Substance popularity}

Figure 2 shows the evolution of the popularity of each substance over their respective timeframe

Generally, the popularity of most substances on the forum follows a downward trend. Several hypotheses can be raised to explain this observation. It could indicate a loss of interest for the substance, due to a decrease in availability or negative health effects reported. Alternatively, the early discussions could have covered a large number of topics, implying that potential consumers are able to find answers to their questions without having to write replies or create new threads. Chronic trends are also present for certain substances (e.g. MDPV, a-PVP, kratom, 25i-NBOMe). This chronic trend could be related to the constant popularity of these substances over the years (EMCDDA, 2015).

In some cases, temporary spikes of interest for a specific substance were noted. In general, the peak of interest is close to the appearance of the substance on the forum. For instance, the peak observed in October 2009 for the synthetic cannabinoid JWH-018 is related to discussions about its short-term and long-term effects. Similarly, mephedrone is characterised by a very important spike between 2009 and 2010 related to the effects of the substance $(>600$ replies for threads created during that timeframe). Such a result could be due to the actual popularity of the substance at that time. On the other hand, the discussions could have been fuelled by the change of legal status of mephedrone following the EMCDDA's risk assessment which led to the international control of mephedrone (Wood \& Dargan, 2013). Plant-based substances are also characterised by spikes in popularity due to threads about their effects and possible addiction problems.

Despite the general downward trend, some upward patterns were sometimes noted. For instance, the sudden increase in replies regarding 2C-B-FLY in October 2009 was due to three threads related to the potential harm caused by the substance following an incident (Power, 2013). Likewise, an increase of interest was noted for mCPP in August 2009. It was caused by a discussion about the results of a Dutch testing program reporting the presence of $\mathrm{mCPP}$ in tablets or its use as an adulterant of MDMA. Given the negative effects of mCPP reported by users (Bossong et al., 2010), MDMA probably supplanted it on the market. 
Figure 2. Popularity of each substance over time

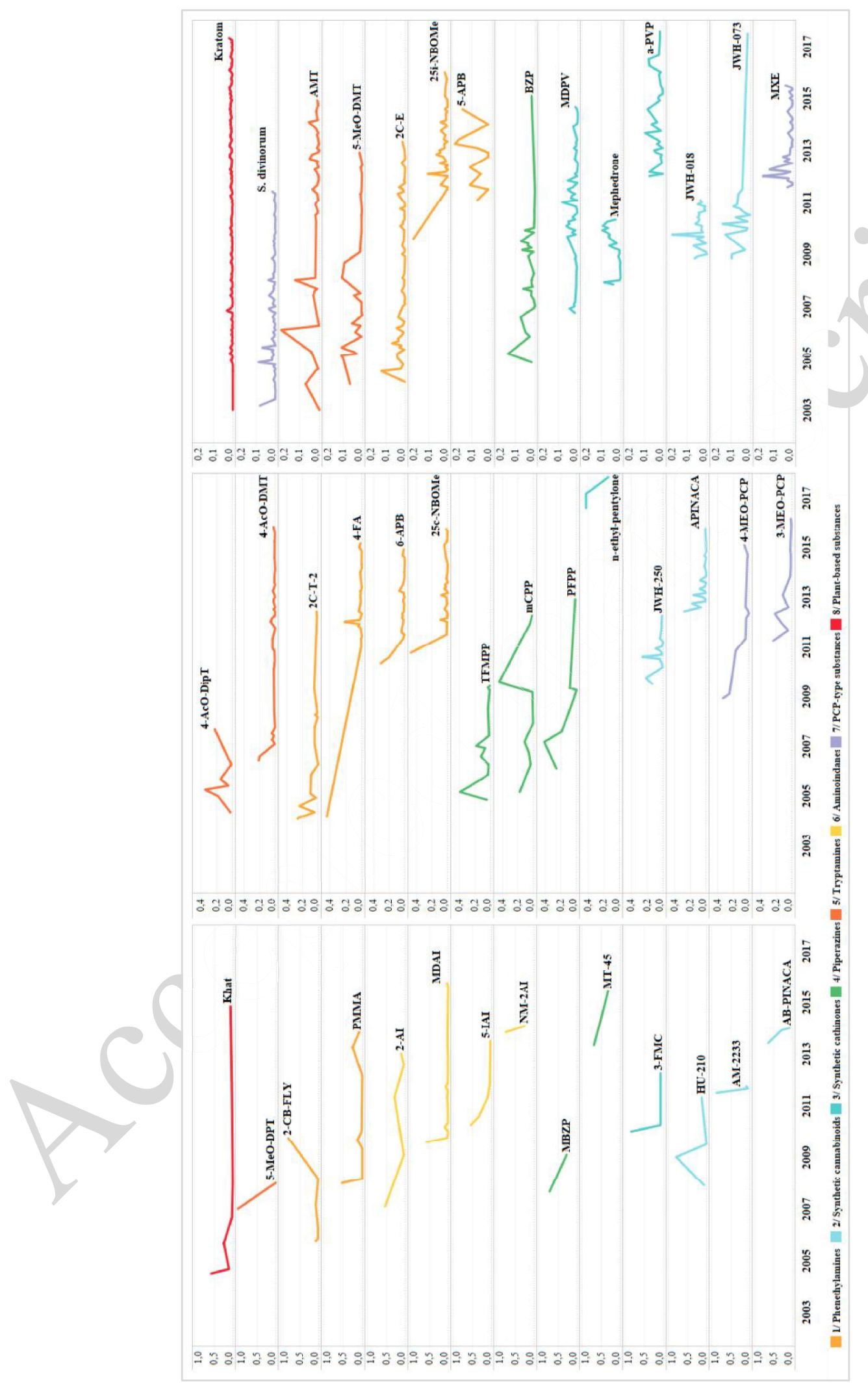




\subsection{Potential of drug forums}

Figure 3 compares the appearance of fifteen substances on the forum to the date of formal notification to the EU early warning system.

Figure 3. Comparison between the presence on the forum and the date of formal notification to the EU Early Warning System (black dot).

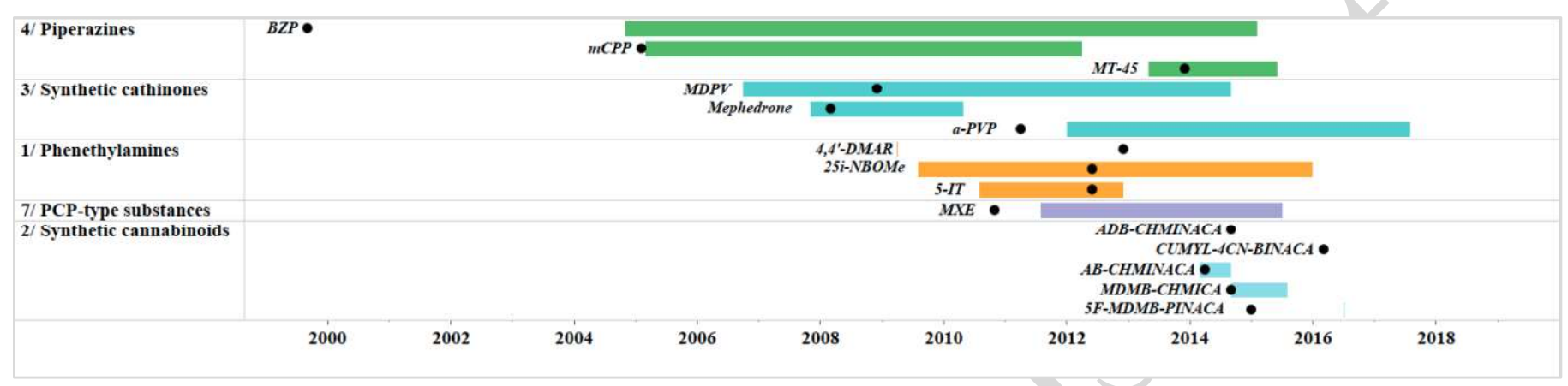

Out of the fifteen substances, nine of them appeared on the forum before or at the same time as their first date of notification to the EU early warning system. Interestingly, all synthetic cannabinoids that were subject to a risk assessment by the EMCDDA were only shorty discussed or not discussed at all on the forum. According to the risk assessment of ADBCHMINACA, CUMYL-4CN-BINACA, 5F-MDMB-PINACA, MDMB-CHMICA and AB-CHMINACA (EMCDDA, 2017b, 2018a, 2018b, 2018c, 2018d), these substances are commonly administered by smoking a cigarette of herbal mixture laced with the substance. Since the ingredients are rarely stated, most users are not aware that they are consuming such a substance and are thus not aware of its name. This could explain why such substances are not discussed on the forum. Furthermore, according to the same risk assessment, no widespread use of these substances is reported. In regards to BZP which appears quite late in comparison to the first date of notification, its first mention was in 1991 by Alexander Shulgin, well before the introduction of online discussion forums. Another interesting result is the very brief appearance of 4,4'-DMAR on the discussion forum three years before its formal notification to the EU early warning system (EMCDDA, 2014). According to the discussion threads, the substance seems to be very difficult to obtain and results in negative sides effects. That might explain why this substance was reported at a later stage.

These results are preliminary; however, they show the potential of online discussion forums to complement early-warning systems.

\section{General discussion and conclusion}

This research demonstrates the potential of analysing online discussion forums to strengthen existing early-warning systems and monitor NPS popularity using an indicator based on data extracted from the forum as a proxy.

The trends observed by analysing data from online discussion forums reflect the scattered information available in the literature. Such a result is in line with the findings of the Psychonaut projects, particularly regarding the exclusiveness of the information gathered online (Psychonaut Web Mapping Research Group, 2005, 2010). Conversely, these projects were fuelled by qualitative analyses and included some time-consuming steps (e.g. reading, classification). A systematic approach - like the one developed in the present research - when periodically implemented could overcome these problems. Indeed, the data collection system is designed in a way which allows the complete reiteration of the process regularly. Combined with temporal data, it enables a monitoring process allowing to follow the intensity of discussions about particular substances over time. More importantly and irrespective of the indicator chosen, the approach offers complementary and useful findings regarding the first appearance of a drug on the market. Out of the fifteen substances that were the subject of risk assessments by the EMCDDA between 1999 and 2017, nine of them appeared on the forum before or at the same time as their first date of notification to the EU early warning system.

Formally, the concept of popularity is defined by the favour of the general public or of a group. In the context of substance consumption, it translates as a large number of consumers. Paradoxically, popularity is sometimes reported in the context of psychoactive substances, while it is not strictly defined. For example, a rising popularity may be explained by the increased 
availability or the effects of a substance (Coppola \& Mondola, 2012). Since the concept of popularity is difficult to define, and thus to assess from data gathered online, the measure of "intensity of discussion" proposed in the present research may be an alternative. Choosing such an indicator as a proxy is not without limitations. However, when observed over time, these indicators may show variations due to positive (e.g. desired effects, no side effects, availability of the substance) or negative discussions (e.g. intoxications, side effects, warnings about substance use). Used within a monitoring system, such an indicator would inform on the evolution - or the non-evolution - of discussions about a substance. In order to strengthen early-warning systems, alerts could also be defined based on sudden rises or temporary spikes, whether the spike is due to positive or negative discussions. The former could inform on the possibility to see this substance more frequently on the market, while the later could trigger preventives measures. In any case, such information would benefit law enforcement agencies, health organizations and policy makers.

While other publicly available data sources (EMCDDA, 2016; UNODC, 2017) on NPS often present aggregated data (e.g. by class of substance), the proposed approach allows to target specific substances on a longer period of time. It also shows the emergence, persistence or transient nature of the substances. This finding is interesting as it could direct the focus of law enforcement resources and research towards a limited number of substances rather than all new substances. Harm reduction initiatives (e.g. prevention campaigns) could also benefit from this knowledge (e.g. addiction problems discussed on the forums) (Corazza, Assi, et al., 2013). Since it will never be possible to anticipate the emergence of all new substances, monitoring systems fuelled by data extracted from online sources might strengthen early-warning initiative already implemented.

Although Drugs-forum was the only forum considered for this study, it is a major discussion forum related to drugs. However, this process could be fuelled by data gathered from other forums. The data collection process can be adapted to other discussion forums, providing a few adaptations due to the fact that all forums are not exactly structured in the same way. This could be particularly interesting if adapted to forums focused specifically on one country as problems may be country specific (see for example the Swedish and Norwegian forums studied respectively by Ledberg (2015) and Bilgrei (2016). In the future and to address these limitations, it could be interesting to combine the results obtained through online monitoring to data from the physical market, such as results of drug-testing programs, waste-water analysis and seizures from customs and border forces (Morelato et al., 2018). As any source of information, discussion forums have limitations and the authors believe that the combination of complementary information would provide policy makers with a more complete picture of the NPS phenomenon.

Finally, in the context of NPS, important differences between classes of substances were noted, in terms of market and interest from consumers. Indeed, some classes are discussed, while others are barely present. It suggests that each class - and even each substance - has its own specificities. A variety of factors may influence how a substance is going to spread or influence the market (Stogner, 2015). Thus, the concept of NPS itself may not be appropriate to describe these substances, as argued by Potter and Chatwin (2018). They provide a critical view of NPS as a category. Considering each class individually, rather than under an umbrella term such as 'novel psychoactive substances' would be a more accurate way to define them and understand the specificity of each class of substances.

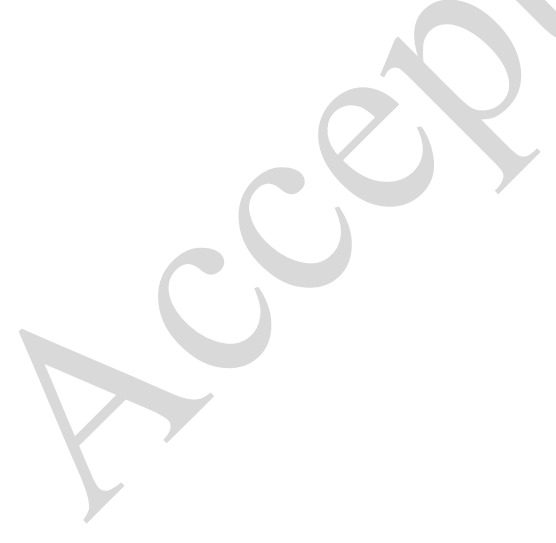




\section{Appendix 1}

Table 3. APPENDIX - Name of the targeted substances

\begin{tabular}{|c|c|c|}
\hline Class & Substance & Also known as \\
\hline \multirow[t]{11}{*}{ 1/ Phenethylamines } & PMMA & 4-methoxy- $N$-methylamphetamine ; 4-MMA \\
\hline & 25c-NBOMe & $\begin{array}{l}\text { 2-(4-chloro-2,5-dimethoxyphenyl)- } N \text {-(2-methoxybenzyl)ethanamine ; } 2 \mathrm{C} \text { - } \\
\text { C-NBOMe }\end{array}$ \\
\hline & 25i-NBOMe & $\begin{array}{l}\text { 4-iodo-2,5-dimethoxy- } N \text {-(2- methoxybenzyl)phenethylamine ; } 2 \mathrm{C}-\mathrm{I}- \\
\text { NBOMe }\end{array}$ \\
\hline & $2 \mathrm{C}-\mathrm{E}$ & 2,5-dimethoxy-4-ethyl-phenethylamine \\
\hline & $2 \mathrm{C}-\mathrm{T}-2$ & 2-[4-(ethylsulfanyl)-2,5-dimethoxyphenyl]ethan-1-amine \\
\hline & 4-FA & para-fluoroamphetamine ; 4-fluoroamphetamine ; 4-FMP \\
\hline & 5-APB & 5-(2-aminopropyl)benzofuran $) y$ \\
\hline & $6-\mathrm{APB}$ & 6-(2-aminopropyl)benzofuran \\
\hline & 2-CB-FLY & 8-bromo-2,3,6,7-benzo-dihydro-difuran-ethylamine \\
\hline & $4,4^{\prime}-\mathrm{DMAR}$ & $\begin{array}{l}\text { 4-methyl-5- (4-methylphenyl)-4,5-dihydrooxazol-2-amine; 4,4'- } \\
\text { Dimethylaminorex; Serotoni }\end{array}$ \\
\hline & $5-\mathrm{IT}$ & 5-(2-Aminopropyl)indole; 5-API; PAL-571 \\
\hline \multirow{10}{*}{$\begin{array}{l}\text { 2/ Synthetic } \\
\text { cannabinoids }\end{array}$} & HU-210 & 1,1-dimethylheptyl-11-hydroxy-tetrahydrocannabinol \\
\hline & JWH-018 & 1-pentyl-3-(1-naphthoyl)indole \\
\hline & JWH-073 & 1-naphthalenyl(1-butyl-1H-indol-3-yl)-methanone \\
\hline & JWH-250 & 1-pentyl-3-(2-methoxyphenylacetyl)indole \\
\hline & AM-2233 & 1-[(N-methylpiperidin-2-yl)methyl]-3-(2-iodobenzoyl)indole \\
\hline & APINACA & $N$-(1-adamantyl)-1-pentyl- $1 H$-indazole-3-carboxamide \\
\hline & AB-PINACA & $\begin{array}{l}N \text {-(1-amino-3-methyl-1-oxobutan-2-yl)-1-pentyl-1 } H \text {-indazole-3- } \\
\text { carboxamide }\end{array}$ \\
\hline & ADB-CHMINACA & $\begin{array}{l}\text { N-(1-amino-3,3-dimethyl-1-oxobutan-2-yl)- 1-(cyclohexylmethyl)-1H- } \\
\text { indazole-3-carboxamide; MAB-CHMINACA }\end{array}$ \\
\hline & $\begin{array}{l}\text { CUMYL-4CN- } \\
\text { BINACA }\end{array}$ & $\begin{array}{l}\text { 1-(4-cyanobutyl)-N-(2-phenylpropan-2-yl) indazole-3-carboxamide; } \\
\text { CUMYL-CYBINACA or SGT-78 }\end{array}$ \\
\hline & AB-CHMINACA & $\begin{array}{l}\text { N-(1-amino-3-methyl-1-oxobutan-2-yl)- 1-(cyclohexylmethyl)-1H- } \\
\text { indazole-3-carboxamide }\end{array}$ \\
\hline
\end{tabular}




\begin{tabular}{|c|c|c|}
\hline & $\begin{array}{l}\text { 5F-MDMB- } \\
\text { PINACA }\end{array}$ & $\begin{array}{l}\text { methyl 2-([1-(5-fluoropentyl)-1H-indazole3-carbonyl]amino)-3,3- } \\
\text { dimethylbutanoate; 5F-ADB }\end{array}$ \\
\hline & MDMB-CHMICA & $\begin{array}{l}\text { methyl 2-[[1-(cyclohexylmethyl)-1H-indole-3- carbonyl] amino]-3,3- } \\
\text { dimethylbutanoate }\end{array}$ \\
\hline \multirow{5}{*}{$\begin{array}{l}\text { 3/ Synthetic } \\
\text { cathinones }\end{array}$} & a-PVP & 1-phenyl-2-(1-pyrrolidinyl)-1-pentanone \\
\hline & MDPV & 3,4-methylenedioxypyrovalerone \\
\hline & Mephedrone & 4-methylmethcathinone \\
\hline & n-ethyl-pentylone & $\beta$-keto-ethylbenzodioxolylpentanamine ; k-EBDP \\
\hline & 3-FMC & $\overbrace{}^{h}(1)$ \\
\hline \multirow[t]{6}{*}{ 4/ Piperazines } & BZP & 1-benzylpiperazine \\
\hline & MBZP & 1-methyl-4-benzylpiperazine \\
\hline & $\mathrm{mCPP}$ & 1-(3-chlorophenyl)piperazine \\
\hline & MT-45 & 1-cyclohexyl-4-(1,2-diphenylethyl)piperazine \\
\hline & PFPP & para-fluorophenylpiperazine \\
\hline & TFMPP & 3-trifluoromethylphenylpiperazine \\
\hline \multirow[t]{5}{*}{ 5/ Tryptamines } & AMT & $\alpha$-methyltryptamine \\
\hline & 4-AcO-DipT & 4-acetoxy- $N, N$-diisopropyltryptamine \\
\hline & 4-AcO-DMT & 4-acetoxy- $N, N$-dimethyltryptamine \\
\hline & 5-MeO-DMT & 5-methoxy- $N, N$-dimethyltryptamine \\
\hline & 5-MeO-DPT & 5-methoxy- $N, N$-dipropyltryptamine \\
\hline \multirow[t]{4}{*}{ 6/ Aminoindanes } & MDAI & 5,6-methylenedioxy-2-aminoindane \\
\hline & NM-2AI & $N$-methyl-2-aminoindane \\
\hline & 2-AI & 2-aminoindane \\
\hline & 5 -IAI & 5-iodo-2-aminoindane \\
\hline \multirow{3}{*}{$\begin{array}{l}\text { 7/ PCP-type } \\
\text { substances }\end{array}$} & MXE & 2-(3-methoxyphenyl)-2-(ethylamino)cyclohexanone \\
\hline & 4-MEO-PCP & 4-methoxyphencyclidine \\
\hline & 3-MEO-PCP & 3-methoxyphencyclidine \\
\hline \multirow{3}{*}{$\begin{array}{l}\text { 8/ Plant-based } \\
\text { substances }\end{array}$} & Khat & Qat, Catha edulis \\
\hline & Kratom & Mitragyna speciosa \\
\hline & Salvia divinorum & - \\
\hline
\end{tabular}




\section{References}

Barratt, M. J., \& Aldridge, J. (2016). Drugs Cryptomarkets [Special issue]. International Journal of Drug Policy, 35, 1-96.

Bilgrei, O. R. (2016). From "herbal highs" to the "heroin of cannabis": Exploring the evolving discourse on synthetic cannabinoid use in a Norwegian Internet drug forum. International Journal of Drug Policy, 29, 1-8. doi:10.1016/j.drugpo.2016.01.011

Bossong, M., Brunt, T., Dijk, J. V., Rigter, S., Hoek, J., Goldschmidt, H., \& Niesink, R. (2010). mCPP: an undesired addition to the ecstasy market. Journal of Psychopharmacology, 24(9), 1395-1401. doi:10.1177/0269881109102541

Brandt, S. D., Braithwaite, R. A., Evans-Brown, M., \& Kicman, A. T. (2013). Aminoindane Analogues. In P. I. Dargan \& D. M. Wood (Eds.), Novel psychoactive substances : classification, pharmacology and toxicology (pp. 261-283). London; Waltham, MA: Elsevier/Academic Press.

Bruno, R., Poesiat, R., \& Matthews, A. J. (2013). Monitoring the Internet for emerging psychoactive substances available to Australia. Drug and Alcohol Review, 32(5), 541-544. doi:10.1111/dar.12049

Brunt, T. M., Atkinson, A. M., Nefau, T., Martinez, M., Lahaie, E., Malzcewski, A., . . Brandt, S. D. (2017). Online test purchased new psychoactive substances in 5 different European countries: A snapshot study of chemical composition and price. International Journal of Drug Policy, 44, 105-114. doi:10.1016/j.drugpo.2017.03.006

Chatwin, C., Measham, F., O'Brien, K., \& Sumnall, H. (2017). New drugs, new directions? Research priorities for new psychoactive substances and human enhancement drugs. International Journal of Drug Policy, 40, 1-5. doi:10.1016/j.drugpo.2017.01.016

Coppola, M., \& Mondola, R. (2012). Synthetic cathinones: Chemistry, pharmacology and toxicology of a new class of designer drugs of abuse marketed as "bath salts" or "plant food". Toxicology Letters, 211(2), 144-149. doi:http://dx.doi.org/10.1016/j.toxlet.2012.03.009

Corazza, O., Assi, S., Simonato, P., Corkery, J., Bersani, F. S., Demetrovics, Z., . . Schifano, F. (2013). Promoting innovation and excellence to face the rapid diffusion of Novel Psychoactive Substances in the EU: the outcomes of the ReDNet project. Human Psychopharmacology: Clinical and Experimental, 28(4), 317-323. doi:10.1002/hup.2299

Corazza, O., Demetrovics, Z., van den Brink, W., \& Schifano, F. (2013). 'Legal highs' an inappropriate term for 'Novel Psychoactive Drugs' in drug prevention and scientific debate. International Journal of Drug Policy, 24(1), 82-83. doi:https://doi.org/10.1016/j.drugpo.2012.06.005

EMCDDA. (2010). Risk assessment of new psychoactive substances - operating guidelines. Retrieved from Luwembourg: Risk assessment of new psychoactive substances — operating guidelines

EMCDDA. (2014). Report on the risk assessment of 4,4'-DMAR in the framework of the Council Decision on new psychoactive substances. Retrieved from Luxembourg:

EMCDDA. (2015). Drug profiles. Retrieved from http://www.emcdda.europa.eu/drug-profiles (access date 10.04.2018)

EMCDDA. (2016). The internet and drug markets (EMCDDA Insights 21). Retrieved from Publications Office of the European Union, Luxembourg: http://www.emcdda.europa.eu/publications/insights/internet-drug-markets

EMCDDA. (2017a). Drugs and the darknet: Perspectives for enforcement, research and policy. Retrieved from Publications Office of the European Union, Luxembourg: http://www.emcdda.europa.eu/publications/joint-publications/drugsand-the-darknet

EMCDDA. (2017b). Report on the risk assessment of methyl 2-[[1-(cyclohexylmethyl)-1H-indole-3-carbonyl]amino]-3,3dimethylbutanoate (MDMB-CHMICA) in the framework of the Council Decision on new psychoactive substances. Retrieved from Luxembourg:

EMCDDA. (2018a). Report on the risk assessment of 1-(4-cyanobutyl)-N-(2-phenylpropan-2-yl)indazole-3-carboxamide (CUMYL-4CN-BINACA) in the framework of the Council Decision on new psychoactive substances. Retrieved from Luxembourg: 
EMCDDA. (2018b). Report on the risk assessment of methyl-2-([1-(5-fluoropentyl)-1H-indazole-3-carbonyl]amino)-3,3dimethylbutanoate (5F-MDMB-PINACA; $5 F-A D B)$ in the framework of the Council Decision on new psychoactive substances. Retrieved from Luxembourg:

EMCDDA. (2018c). Report on the risk assessment of N-(1-amino-3-methyl-1-oxobutan-2-yl)-1-(cyclohexylmethyl)-1Hindazole-3-carboxamide (AB-CHMINACA) in the framework of the Council Decision on new psychoactive substances. Retrieved from Luxembourg:

EMCDDA. (2018d). Report on the risk assessment of N-(1-amino-3,3-dimethyl-1-oxobutan-2-yl)-1-(cyclohexylmethyl)-1Hindazole-3-carboxamide (ADB-CHMINACA) in the framework of the Council Decision on new psychoactive substances. Retrieved from Luxembourg:

EMCDDA, \& Eurojust. (2016). New psychoactive substances in Europe. Legislation and prosecution - current challenges and solutions Retrieved from Luxembourg: http://www.emcdda.europa.eu/publications/joint/eurojust/npslegislation-and-prosecution

EMCDDA, \& Europol. (2016). EU Drug Markets Report: In-Depth Analysis. Retrieved from Luxembourg:

Feng, L.-Y., Battulga, A., Han, E., Chung, H., \& Li, J.-H. (2017). New psychoactive substances of natural origin: A brief review. Journal of Food and Drug Analysis, 25(3), 461-471. doi:10.1016/j.jfda.2017.04.001

Gibbons, S., \& Arunotayanun, W. (2013). Natural Product (Fungal and Herbal) Novel Psychoactive Substances. In P. I. Dargan \& D. M. Wood (Eds.), Novel psychoactive substances : classification, pharmacology and toxicology (pp. 345-362). London ; Waltham, MA: Elsevier/Academic Press.

Greene, S. L. (2013). Tryptamines. In P. I. Dargan \& D. M. Wood (Eds.), Novel psychoactive substances : classification, pharmacology and toxicology (pp. 363-381). London ; Waltham, MA: Elsevier/Academic Press.

King, L. A. (2013). Legal classification of novel psychoactive substances - An international comparison In P. I. Dargan \& D. M. Wood (Eds.), Novel psychoactive substances : classification, pharmacology and toxicology (pp. 3-27). London, UK ; Waltham, US: Elsevier/Academic Press.

Kjellgren, A., Henningsson, H., \& Soussan, C. (2013). Fascination and Social Togetherness - Discussions about Spice Smoking on a Swedish Internet Forum. Substance Abuse: Research and Treatment, 7, 190-198. doi:10.4137/sart.S13323

Kruithof, K., Aldridge, J., Décary-Hétu, D., Sim, M., Dujso, E., \& Hoorens, S. (2016). Internet-facilitated drugs trade - An analysis of the size, scope and the role of the Netherlands. Retrieved from Santa Monica, CA ; Cambride, UK: http://www.rand.org/pubs/research_reports/RR1607.html

Ledberg, A. (2015). The interest in eight new psychoactive substances before and after scheduling. Drug and Alcohol Dependence, 152, 73-78. doi:10.1016/j.drugalcdep.2015.04.020

Meyers, K., Kaynak, Ö., Bresani, E., Curtis, B., McNamara, A., Brownfield, K., \& Kirby, K. (2015). The availability and depiction of synthetic cathinones (bath salts) on the Internet: do online suppliers employ features to maximize purchases? International Journal of Drug Policy, 26(7), 670-674. doi:10.1016/j.drugpo.2015.01.012

Morelato, M., Broséus, J., De Grazia, A., Tahtouh, M., Esseiva, P., \& Roux, C. (2018). Forensic drug intelligence and the rise of cryptomarkets. Part II: Combination of data from the physical and virtual markets. Forensic Science International, 288, 201-210. doi:https://doi.org/10.1016/j.forsciint.2018.05.002

Pineau, T., Schopfer, A., Grossrieder, L., Broséus, J., Esseiva, P., \& Rossy, Q. (2016). The study of doping market: How to produce intelligence from Internet forums. Forensic Science International, 268, 103-115. doi:10.1016/j.forsciint.2016.09.017

Potter, G. R., \& Chatwin, C. (2018). Not particularly special: critiquing 'NPS' as a category of drugs. Drugs: Education, Prevention and Policy, 25(4), 329-336. doi:10.1080/09687637.2017.1411885

Power, M. (2013). Drugs unlimited : the web revolution that's changing how the world gets high (First U.S. Edition. ed.). New York: Thomas Dunne Books.

Psychonaut Web Mapping Research Group. (2005). The Psychonaut 2002 project - Final report. Retrieved from Londres: http://ec.europa.eu/health/ph_projects/2002/drug/drug_2002_09_en.htm 
Psychonaut Web Mapping Research Group. (2010). Psychonaut Web Mapping Project: Final Report. Retrieved from

Rossy, Q., \& Décary-Hétu, D. (2018). Internet traces and the analysis of online illicit markets. In Q. Rossy, D. Décary-Hétu, O. Delémont, \& M. Mulone (Eds.), Routledge International Handbook of Forensic Intelligence and Criminology (pp. 249-263). Abingdon, UK: Routledge.

Sedefov, R., Gallegos, A., Mounteney, J., \& Kenny, P. (2013). Monitoring novel psychoactive substances - A global perspective. In P. I. Dargan \& D. M. Wood (Eds.), Novel psychoactive substances : classification, pharmacology and toxicology (pp. 29-54). Londres, UK ; Waltham, US: Elsevier/Academic Press.

Soussan, C., \& Kjellgren, A. (2016). The users of Novel Psychoactive Substances: Online survey about their characteristics, attitudes and motivations. International Journal of Drug Policy, 32, 77-84. doi:10.1016/j.drugpo.2016.03.007

Stogner, J. M. (2015). Predictions instead of panics: the framework and utility of systematic forecasting of novel psychoactive drug trends. The American Journal of Drug and Alcohol Abuse, 41(6), 519-526. doi:10.3109/00952990.2014.998367

UNODC. (2017). World Drug Report 2017. Market analysis of synthetic drugs - Amphetamine-type stimulants, new psychoactive substances (Sales No. E.17.XI.6). Retrieved from United Nations publication, Vienna: https://www.unodc.org/wdr2017/en/ats.html

Van Hout, M. C., \& Hearne, E. (2017). New psychoactive substances (NPS) on cryptomarket fora: An exploratory study of characteristics of forum activity between NPS buyers and vendors. International Journal of Drug Policy, 40, 102110. doi:10.1016/j.drugpo.2016.11.007

Watterson, L. R., \& Foster Olive, M. (2014). Synthetic Cathinones and Their Rewarding and Reinforcing Effects in Rodents. Advances in Neuroscience, 2014, 9. doi:10.1155/2014/209875

Wilson-Hohler, M., Fathy, W., \& Mozayani, A. (2016). How Present Synthetic Cannabinoids Can Help Predict Symptoms in the Future. MOJ Toxicology, 2(1), 00029. doi:10.15406/mojt.2016.02.00029

Wood, D. M., \& Dargan, P. I. (2013). Mephedrone. In P. I. Dargan \& D. M. Wood (Eds.), Novel psychoactive substances : classification, pharmacology and toxicology (pp. 211-231). Londres, UK ; Waltham, US: Elsevier/Academic Press. 